\title{
Maladministrasi Birokrasi di Indonesia Dalam Perspektif Sejarah
}

\author{
Rodi Wahyudi \\ Fakultas Ilmu Ekonomi dan Ilmu Sosial, Universitas Islam Negeri Sulthan Syarif Kasim Riau \\ e-mail: rodi.wahyudi@uin-suska.ac.id
}

\begin{abstract}
Memahami pola fikir penguasa, moral pegawai dan perilaku penyelenggara pemerintahan dapat diketahui melalui akar sejarah suatu bangsa. Pegangan mereka tentang etika administrasi dan ketaatan terhadap kode etik pelayanan publik dapat dijadikan sebagai indikator kualitas pelayanan kepada masyarakat. Tulisan ini bertujuan untuk membahas tentang perilaku maladministrasi birokrasi di Indonesia dalam pendekatan sejarah. Analisis terhadap sumber ilmiah yang berkaitan dengan sejarah merupakan kaedah utama yang digunakan dalam tulisan ini. Peneliti membagi sejarah maladministrasi birokrasi menjadi lima zaman, yaitu zaman pra kolonial, zaman penjajahan kolonial Belanda, zaman penjajahan Jepang, zaman Orde Lama, zaman Orde Baru dan zaman pasca reformasi. Hasil analisis kajian ini menunjukkan bahwa administrator publik lebih fokus melayani kepentingan penguasa daripada melayani rakyat. Istilah birokrasi yang digunakan memang berubah mengikut zaman, birokrasi priyayi \& abdi dalem, birokrasi pangreh praja, birokrasi modern, tetapi perilaku mereka tetap melayani rezim yang berkuasa. Walaupun pasca reformasi telah dilakukan perubahan peraturan perundangan berkaitan dengan pelayanan publik, namun dalam tataran perilaku maladministrasi birokrasi masih gagal diatasi. Mencegah perilaku maladministrasi birokrasi melalui penanaman dan pengamalan ajaran agama dan norma sosial adalah antara solusi yang dapat dilakukan oleh pihak pemerintah agar cita-cita reformasi birokrasi dapat terwujud
\end{abstract}

Keywords: maladministrasi, birokrasi, administrasi, pelayanan publik.

Abstrak

Understanding the rational mindset, employee morale and governance behavior can be known through the historical roots of a nation. Their grip on administrative ethics and adherence to the code of public service ethics can be used as indicators of quality of service to the community. This paper aims to discuss the bureaucratic maladministration behavior in Indonesia in the historical approach. Analysis of scientific sources relating to history is the main method used in this paper. Researchers divided the history of bureaucratic maladministration into five epochs, namely the pre-colonial era, the Dutch colonial era, the Japanese colonial era, the Old Order era, the New Order era and the post-reform era. The results of the analysis of this study indicate that public administrators are more focused on serving the interests of the authorities rather than serving the people. The term bureaucracy used has indeed changed with the times, bureaucracy of priyayi and servants, bureaucracy of civil service, modern bureaucracy, but their behavior still serves the ruling regime. Even though post-reformation, there has been a change in legislation relating to public services, but at the level of bureaucratic maladministration behavior, it has still failed to overcome. Preventing bureaucratic maladministration behavior through planting and practicing religious teachings and social norms is a solution that can be done by the government so that the ideals of bureaucratic reform can be realized.

Kata Kunci : maladministration, bureaucracy, administration, public services. 


\section{PENDAHULUAN}

Birokrasi memiliki peranan penting dalam menjalankan berbagai tugas pemerintahan dalam suatu negara. Selain menyediakan pelayanan yang berkualitas kepada masyarakat, birokrasi juga diberi tanggungjawab untuk melaksanakan keputusan politik pemerintah dalam mewujudkan rakyat yang sejahtera. Sehubungan dengan hal itu, birokrasi harus melaksanakan program pembangunan negara kearah peningkatan kualitas hidup rakyat, memberi peluang yang adil untuk mendapatkan akses pendidikan, peluang untuk meningkatkan pendapatan, menyediakan pelayanan kesehatan dan kemudahan lainnya. Namun demikian, di negara manapun tidak selamanya birokrasi mampu menjalankan peranannya dengan baik. Pembangunan suatu negara akan berhasil apabila didukung oleh birokrasi yang profesional dan amanah (Ibnu Khaldun 1332-1406 M). Hampir seluruh program pembangunan tidak bisa lepas dari peranan birokrasi dalam mensukseskannya. Sehubungan dengan itu, usaha perbaikan kualitas pelayanan publik adalah satu perkara yang tidak bisa dianggap remeh. Buruknya perilaku birokrasi akan memberikan dampak yang luas dalam kehidupan ekonomi, politik, sosial, budaya dan agama di suatu negara.

Begitu pula dalam kehidupan politik, maladministrasi birokrasi bisa menjadi isu oleh partai oposisi untuk mengkritik pemerintah. Kegagalan pemerintah memperbaiki perilaku maladministrasi birokrasi dapat menyebabkan sistem administrasi menjadi tidak stabil. Sama halnya dalam kehidupan sosial, maladministrasi birokrasi mengakibatkan tekanan psikologi kepada masyarakat yang datang berurusan ke kantor pemerintah. Sebelum berangkat ke kantor mereka telah membayangkan susahnya urusan, menunggu lama, tidak jelas berapa rupiah harus dibayar, apa syarat yang perlu disiapkan, serta diperparah lagi oleh sifat pegawai yang kasar dan kurang ramah terhadap masyarakat.

Maladministrasi birokrasi diartikan sebagai perilaku buruk pegawai pemerintah dalam memberikan pelayanan kepada masyarakat. Maju atau mundurnya suatu bangsa sangat bergantung pada baik atau buruknya perilaku birokasi. Kewibawaan pemerintah di mata rakyat sangat erat hubungannya dengan kemampuan birokrasi dalam memenuhi tuntutan dan aspirasi rakyat serta mampu memberikan jalan keluar terhadap masalah yang sedang dihadapi oleh rakyat. Konsep maladministrasi birokrasi lahir pada akhir abad ke-19 sebagai istilah yang menunjukkan kegagalan birokrasi dalam mengurus urusan rakyat, kurang inisiatif dan kurang sifat tanggungjawab dari pegawai pemerintah. Penelitian mengenai fenomena maladministrasi birokrasi telah dimulai sejak tahun 1917 oleh seorang ilmuan dari Inggeris bernama Hayward. Beliau telah melakuan penelitian tentang fenomena maladministrasi di Inggeris dan memaparkan bahwa sejak pekerjaan sebagai pegawai pemerintah termasuk dalam kategori pekerjaan profesional, maka pegawai pemerintah yang bekerja dalam institusi birokrasi dituntut untuk bekerja dengan profesional dan bertanggungjawab.

Konsep maladministrasi birokrasi semakin berkembang setelah berdirinya institusi ombudsman di Scandinavia pada tahun 1950. Ombudsman adalah satu institusi pemerintah yang berfungsi untuk menerima laporan pengaduan dari masyarakat atas dugaan ketidakpuasan mereka menerima pelayanan publik. Selepas tahun 1960, pemerintah Inggeris pula mendirikan institusi ombudsman. Antara sebab disusun draf rancangan undang-undang Ombudsman adalah masalah maladministrasi birokrasi yang harus segera diselesaikan di Inggeris. Antara jenis maladministrasi birokrasi yang berleluasa pada masa itu ialah tidak adil dalam memberikan pelayanan, kecuaian terhadap tugas, pengabaian tanggungjawab, kelewatan waktu menyelesaikan dokumen, kejahatan dan perilaku buruk lainnya di kantor.

Secara etimologis Ahmad Basuki (2011) menyatakan bahwa maladministrasi berasal dari bahasa latin, mal berarti buruk atau jahat dan administrare ertinya melayani. Birokrasi pula bermakna kantor pemerintah. Dengan demikian maladministrasi birokrasi membawa maksud pelayanan yang buruk atau kejahatan dilakukan oleh pegawai pemerintah. Maladministrasi birokrasi merupakan perbuatan berat sebelah, kelewatan waktu, tidak memberi tumpuan, kejahatan, perilaku buruk dalam proses pelayanan oleh pegawai pemerintah. Secara mudah maladministrasi birokrasi dapat diartikan sebagai kegagalan 
dalam memberikan pelayanan kepada masyarakat. Maladministrasi menurut Undang-Undang Ombudsman Republik Indonesia adalah: perilaku atau perbuatan melawan hukum, melampaui wewenang, menggunakan wewenang untuk tujuan lain dari yang menjadi tujuan wewenang tersebut, termasuk kelalaian atau pengabaian kewajiban hukum dalam penyelenggaraan pelayanan publik yang dilakukan oleh penyelenggara negara dan pemerintahan yang menimbulkan kerugian materiil dan/atau immateriil bagi masyarakat dan orang perseorangan (Pasal 1 ayat 3 ).

Di Indonesia, antara yang paling awal mengembangkan wacana tentang maladministrasi birokrasi adalah Hartono et.al (2003), beliau menulis bahawa maladministrasi adalah perilaku yang tidak wajar, tidak sopan dan kurang peduli terhadap masalah masyarakat, perbuatan penyalahgunaan kekuasaan, tidak adil, diskriminatif, keputusan yang tidak masuk akal dan bertentangan dengan undang-undang. Berdasarkan perubahan zaman penguasa di Indonesia, penulis tertarik untuk melakukan penelitian bagaimana 'maladministrasi birokrasi di Indonesia dalam perspektif sejarah.

\section{METODE}

Penelitian ini menggunakan dua metode yaitu studi kepustakaan dan metode kuantitatif. Metode studi kepustakaan berdasarkan sumber dari buku dan jurnal. Hasil pembacaan penulis dari sumber ilmiah dirangkai dan diceritakan secara kronologis dan dilanjutkan dengan interpretasi dari data sekunder tersebut. Studi kepustakaan penulis gunakan untuk menerangkan sejarah maladministrasi birokrasi dari masa pra-kolonial sampai masa orde baru. Adapun masa sesudah reformasi, penulis buktikan dengan data kuantitaif melalui angket yang telah dibagikan kepada 250 orang pegawai yang bekerja di beberapa kantor pelayanan publik di Kota Pekanbaru. Angket tersebut mengukur perilaku maladministrasi birokrasi.

\section{HASIL DAN PEMBAHASAN}

Sejarah Indonesia dimulai sejak abad ke 5 Masehi yaitu kerajaan Kutai di Kalimantan Timur dan kerajaan Tarumanegara di Jawa Barat. Dari peninggalan kedua kerajaan ini, agama dan kebudayaan Hindu sangat berpengaruh pada ketika itu. Ajaran Hindu inilah yang diamalkan oleh raja kerajaan Mataram kuno ketika berkuasa di Indonesia. Kerajaan seolah-olah milik perseorangan, raja hidup bermewah-mewah sedangkan rakyat dianggap sebagai budak. Raja berhak menetapkan hukum atas harta dan barang milik rakyat. Hasil pertanian rakyat adalah untuk penguasa dan rakyat bekerja untuk kesejahteraan penguasa. Birokrasi kerajaan bertugas untuk melaksanakan semua keinginan raja. Pada masa kerajaan Mataram kuno belum ada lagi istilah birokrasi (istilah birokrasi mulai populer pada abad ke 19 M). Namun, kelompok manusia yang bekerja untuk melaksanakan kebijakan kerajaan sebagai makna birokrasi sudah wujud. Mereka dikenal dengan istilah kumpulan priyayi dan abdi dalem. Rakyat jelata disebut dengan istilah wong cilik. Hubungan antara birokrasi kerajaan (priyayi dan abdi dalem) dengan rakyat (wong cilik) disebut dengan istilah patronclient, artinya kumpulan priyayi dan abdi dalem bertindak sebagai majikan dengan hak-hak istimewa yang mereka miliki, sementara wong cilik adalah rakyat yang dituntut agar berkhidmat kepada mereka. Penjelasan sejarah maladministrasi birokrasi di Indonesia telah penulis ringkas dalam Tabel 1. 


\section{Tabel 1. Corak Perbandingan Maladministrasi Birokrasi Berdasarkan Zaman Penguasa di Indonesia

\begin{tabular}{cc}
\hline Zaman & Corak Maladministrasi Birokrasi \\
\hline Pra Kolonial & $\begin{array}{r}\text { 1. } \text { Birokrasi memaksa rakyat (wong cilik) } \\
\text { membayar cukai (upeti), kerja paksa dan } \\
\text { harus ikut dalam peperangan }\end{array}$ \\
& 2. Birokrasi bekerja sebagai pelayan raja
\end{tabular}

\begin{tabular}{|c|c|}
\hline $\begin{array}{l}\text { Kolonial } \\
\text { Belanda }\end{array}$ & $\begin{array}{l}\text { 1. Birokrasi bekerja demi kepentingan } \\
\text { Belanda } \\
\text { 2. Birokrasi menindas rakyat melalui kerja } \\
\text { paksa (rodi) } \\
\text { 3. Kantor pelayanan hanya untuk pegawai } \\
\text { Belanda dan rakyat yang bekerja sebagai } \\
\text { kakitangan Belanda }\end{array}$ \\
\hline $\begin{array}{l}\text { Penjajah } \\
\text { Jepun }\end{array}$ & $\begin{array}{l}\text { 1. Birokrasi bekerja untuk kepentingan } \\
\text { Penjajah Jepang } \\
\text { 2. Birokrasi menindas rakyat melalui kerja } \\
\text { paksa (romusha) } \\
\text { 3. Birokrasi merampas hasil pertanian } \\
\text { rakyat untuk keperluan logistik perang } \\
\text { tentera Jepang melawan Sekutu }\end{array}$ \\
\hline Orde Lama & $\begin{array}{l}\text { 1. Birokrasi tidak memiliki kompetensi } \\
\text { dalam bekerja } \\
\text { 2. Birokrasi terkotak-kotak mengikut } \\
\text { fahaman politik }\end{array}$ \\
\hline Orde Baru & $\begin{array}{l}\text { 1. Birokrasi sebagai elit penguasa } \\
\text { 2. Birokrasi korup } \\
\text { 3. Sistem rekrutmen pegawai bukan atas } \\
\text { dasar kompetensi }\end{array}$ \\
\hline $\begin{array}{l}\text { Era } \\
\text { Reformasi }\end{array}$ & $\begin{array}{l}\text { 1. Birokrasi korup } \\
\text { 2. Layanan birokrasi tidak adil } \\
\text { 3. Mengekalkan budaya buruk birokrasi } \\
\text { dan menutup diri terhadap tuntutan } \\
\text { perubahan }\end{array}$ \\
\hline
\end{tabular}

Sumber: Diolah dari Lijan (2008), Agus Dwiyanto et.al (2008), Anthony Reid (2011).

\subsection{Maladministrasi Birokrasi Zaman Pra Kolonial}

Pada abad ke-6 dan ke-7 M dapat dikatakan sebagai abad yang paling merosot dalam sejarah kehidupan umat manusia di seluruh dunia. Semakin hari kemerosotan manusia makin bertambah parah. Manusia sudah kehilangan perasaan untuk dapat membedakan antara yang baik dan buruk. Nilai moral, 
norma dan etika dalam kehidupan telah lama lenyap. Kebanyakan manusia ketika itu memilih hidup untuk bersenang-senang dan bergaul dengan raja-raja dan kaum bangsawan. Mereka lebih senang bekerjasama dengan para penguasa dalam melakukan kejahatan, kezaliman dan memakan harta orang lain. Banyak pusat-pusat peradaban dan ilmu pengetahuan serta birokrasi pemerintahan berubah menjadi gelanggang pertarungan, keruntuhan moral, kekacauan dan kebiadaban penguasa. Hal ini terjadi karena manusia telah kehilangan nilai dan tujuan hidupnya (Syed Abul Hasan Ali An Nadwy 1951). Apa yang berlaku dalam tamadun manusia pada abad ke 6 dan 7 M, juga tidak jauh berbeda dengan keadaan tamadun manusia di Indonesia pada masa awal berdirinya kerajaan kuno di Pulau Kalimantan, Sumatera, Sulawesi dan Jawa pada akhir abad ke $5 \mathrm{M}$.

Sistem yang dibentuk oleh kerajaan Jawa kuno menggambarkan bahwa birokrasi adalah untuk kepentingan raja. Tugas utama pegawai adalah mempertahankan kekuasaan raja dan menyediakan sumber kekayaan bagi raja. Inilah awal mulanya muncul perilaku maladministrasi birokrasi dalam sejarah bangsa Indonesia dalam bentuk penyalahgunaan kekuasaan. Birokrasi tidak menunaikan hak-hak rakyat malah sebaliknya menindas rakyat. Menurut Syed Abul Hasan Ali An Nadwy (1951), pada abad ke 6 M bangsa India sedang mengalami keruntuhan moral yang sangat parah. Pada masa itu bangsa India sama dengan bangsa lain (Mesir, Romawi, Cina dan Persia) yang sedang dilanda keruntuhan moral. Namun bangsa India jauh lebih rusak daripada bangsa lainnya disebabkan oleh banyaknya jumlah tuhan yang disembah, banyaknya penyimpangan dalam bidang seks dan perbedaan status sosial mengikut kasta (brahmana, satria, waisya dan sudra). Kasta Brahmana (kumpulan penguasa dan pendeta) diperbolehkan untuk mengambil harta yang dimiliki oleh kasta sudra tanpa ada dosa. Hal ini karena dalam ajaran Hindu, kasta sudra tidak berhak memiliki harta sedikit pun. Kasta Sudra dinyatakan lebih rendah daripada hewan. Kelas Brahmana akan sentiasa terhapus seluruh dosa mereka walaupun membunuh seluruh kasta dibawahnya.

Hans dan Tilman (1992) menggambarkan bahwa birokrasi kerajaan tidak dibayar gaji oleh raja, upah mereka diperoleh dengan cara merampas hasil pertanian rakyat. Pandangan Hans dan Tilman (1992) sesuai dengan pendapat Miftah Thoha (2008) yang menyatakan bahwa pada zaman kerajaan yang kekuasaan raja bersifat absolut, rakyat tidak mendapat layanan apa-apa dari pihak kerajaan, tidak ada pelayanan publik yang disediakan, yang ada hanyalah penindasan dan kezoliman birokrasi. Dalam bahasa yang lain Lijan (2008) menambahkan bahwa secara sosiologis, kumpulan priyayi dan abdi dalem adalah satu kumpulan yang termasuk dalam sistem birokrasi kerajaan, mereka diberi kewenangan untuk membuat keputusan di pengadilan dan menjaga keamanan kerajaan. Kewenangan yang diberikan oleh raja kepada birokasi tersebut lebih menekankan fungsi kekuasaan daripada fungsi pelayanan kepada masyarakat.

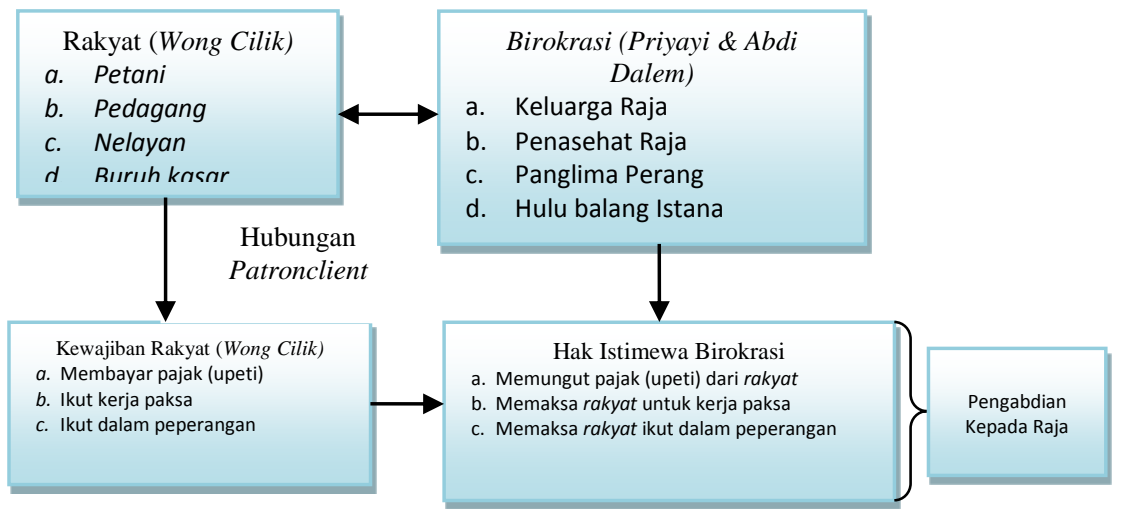

Gambar 1. Hubungan patronclient antara Birokrasi priyayi \& abdi dalem dengan Wong Cilik

(Sumber: Diubah dari Bernhard Dahm,1970, Hans \& Tilman,1992 dan Lijan, 2008) 


\subsection{Maladministrasi Birokrasi Zaman Kolonial Belanda}

Belanda datang bukan untuk membangunkan rakyat Indonesia, mereka datang semata-mata untuk menjajah, mengeksploitasi kekayaan alam, mencari keuntungan yang sebesar-besarnya bagi negara Belanda. Untuk mencapai tujuan tersebut, kolonial Belanda telah membentuk sistem birokrasi dengan cara menggabungkan dua sistem birokrasi yaitu birokrasi Belanda dengan birokrasi priyayi. Menurut Anthony Reid (2011), kolonial Belanda membawa sistem birokrasi dari negara mereka untuk diterapkan di Indonesia dengan melakukan perubahan mengikut lingkungan tanah jajahan. Misalnya di Makasar, Sulawesi Selatan kolonial Belanda telah membangun beberapa kantor seperti pengadilan, daerah kabupaten, kantor dinas sosial (weeskamer en vogdijraad), Badan Pemeriksa Keuangan (inspectie van financieen), Kantor telekomunikasi (bestuur telefoondienst), kantor kesehatan (gewestelijik gouvernements arts), kantor pengairan (waterstaat kantoor), kantor imigrasi (immigratie kantoor), kantor pendidikan (inspectie van onderwijs), kantor urusan tanah (kadaster kantoor), kantor pertanian (dienst van landbouw), kantor pajak, kantor pos dan telegram (posten telegraafkantoor) dan perusahaan air minum (waterleiding). Satu hal yang perlu diingat bahwa kantor yang mereka bentuk bukan untuk memberi pelayanan kepada rakyat, melainkan pelayanan untuk pegawai dan warga Belanda serta rakyat peribumi yang bekerja dengan Belanda.

Birokrasi kolonial Belanda yang berasal dari kumpulan priyayi diberi tanggungjawab mengurus urusan rakyat peribumi. Tujuan Belanda memilih birokrasi priyayi dengan asumsi bahwa rakyat lebih taat kepada birokrasi priyayi berbanding pegawai Belanda. Mempekerjakan kumpulan priyayi adalah alternatif paling mudah dan murah daripada mendatangkan orang Belanda ke Indonesia. Dalam waktu yang sama kolonial Belanda berusaha membelokkan kepatuhan kumpulan priyayi dari ketaatan kepada raja menjadi taat kepada Belanda.

\subsection{Maladministrasi Birokrasi Zaman Penjajahan Jepang}

Maladministrasi birokrasi di zaman Jepang sama dengan zaman Belanda yaitu penyalahgunaan kekuasaan. Bukan pelayanan publik dari penjajah Jepang diperolehi rakyat, malahan rakyat diwajibkan untuk menyerahkan sebagian besar hasil pertanian mereka kepada tentara Jepang sebagai logistik mereka berperang melawan tentara sekutu. Jepang juga melakukan kerjasama dengan penguasa lokal, seperti para raja di sumatera timur, para penghulu di Minangkabau, uleebalang di Aceh dan penguasa priyayi di Jawa. Penjajah Jepang belajar dari pengalaman Belanda bahwa tidak mungkin menguasai wilayah yang luas tanpa mendapat dukungan dari warga peribumi.

Menurut Zamakhsyari Dhofier (1984), pada awalnya rakyat Indonesia menyambut baik kedatangan Jepang, hal ini dilihat dari kerjasama yang diberikan oleh tokoh pejuang kemerdekaan, Soekarno dan Mohammad Hatta. Jepang mulai aktif membujuk rakyat dengan membentuk organisasi rakyat, walaupun sebenarnya bertujuan untuk kepentingan Jepang dalam Perang Dunia II. Oganisasi itu ialah Gerakan Tiga A, Pusat Tenaga Rakyat, Jawa Hokokai, Seinendan, Keibodan, Fujinkai, Heiho, MIAI (Majelis Islam A'la Indonesia), kantor urusan agama dan pembentukan jawatan kuasa penyelidik usaha persiapan kemerdekaan republik Indonesia (BPUPKI). Penjajah Jepang tidak sempat menyediakan pelayanan untuk rakyat Indonesia, selain disebabkan masa mereka menjajah Indonesia terlalu singkat yaitu kurang lebih 3,5 tahun, penjajah Jepang juga lebih memberikan tumpuan bagaimana menyiapkan tentara dan kebutuhan perang melawan Amerika dan sekutunya.

\subsection{Maladministrasi Birokrasi Zaman Orde Lama}

Walaupun bangsa Indonesia sudah lepas dari penjajahan bangsa lain, tetapi maladministrasi birokrasi masih tetap wujud. Bentuk maladministrasi birokrasi pada zaman orde lama adalah tidak profesional dalam bekerja, tidak mampu memberikan pelayanan kepada masyarakat dan birokrasi tidak netral dan tidak ada sifat disiplin. Terdapat dua persoalan yang menjadi dilema dalam sistem birokrasi 
yaitu pertama, bagaimana cara menempatkan pegawai yang ikut berjuang untuk kemerdekaan Indonesia, tetapi tidak bisa bekerja di kantor pemerintah. Kedua, bagaimana pula menempatkan pegawai yang telah lama bekerja dengan kolonial Belanda yang memiliki pengalaman, tetapi mereka dianggap berkhianat terhadap bangsa Indonesia (Prajudi Atmosudirdjo 1980).

Untuk mengurangi perilaku maladministrasi birokrasi maka Presiden Soekarno meminta Edward Litchfield dekan School of Bussiness and Public Administration di Universitas Cornell untuk melakukan penelitian untuk menyusun sistem administrasi yang baru. Edward Litchfield telah melakukan kajian dan mengumpulkan data di kawasan pulau Jawa dan sebagian Sumatera, Bali, Makasar dan Sulawesi Utara yang melibatkan sebanyak 200 orang yang terdiri dari pegawai, tokoh masyarakat, wartawan dan masyarakat (Wajong 1962). Usaha tersebut dilanjutkan dengan didirikannya Kantor Urusan Pegawai (KUP) yang khusus menangani rekrutmen pegawai baru (Samodra Wibawa 2001). Pada tahun 1957 pula, dibentuk lagi satu kantor yaitu Lembaga Administrasi Negara (LAN) sebagai satu institusi yang berfungsi untuk memberikan pendidikan dan pelatihan pegawai.

\subsection{Maladministrasi Birokrasi Zaman Orde Baru}

Penambahan jumlah pegawai secara besar-besaran semasa pemerintahan orde baru dalam pandangan Agus Dwiyanto et.al (2008) membawa dua makna. Pertama, menyediakan lowongan pekerjaan baru sehingga mengurangi angka pengangguran. Selama pemerintahan orde baru berkuasa, melantik pegawai sehingga melebihi keperluan. Penerimaan pegawai dilakukan tanpa memperhatikan aspek kompetensi, integritas, profesionalisme dan keperluan kantor pemerintah. Kedua, birokrasi mengontrol pihak yang mencoba mengkritik dan menentang kebijakan pemerintah. Kesalahan sistem rekrutmen menyebabkan kualitas pelayanan publik tidak dapat ditingkatkan. Pegawai yang diterima atas hubungan keluarga atau lulus karena disogok. Akibat dari kesalahan sistem rekrutmen tersebut adalah pegawai menjadi lebih menduhulukan keinginan atasan dan kurang memberi perhatian terhadap keperluan masyarakat.

Wewenang dan kuasa yang dimiliki oleh birokrasi akhirnya telah membuka pintu terjadi perilaku maladministrasi birokrasi. Penyalahgunaan kekuasaan dan perilaku korupsi merupakan ciri yang paling jelas dalam institusi birokrasi. Faktor penyebabnya adalah gaji pegawai sangat tidak layak. Pada zaman Soeharto, gaji yang diterima tidak mencukupi keperluan pokok selama sebulan. Pegawai yang masih bujang mendapat $10 \mathrm{~kg}$ beras perbulan dan yang telah berkeluarga mendapat $30 \mathrm{~kg}$. Sudah menjadi kebiasaan pegawai mempunyai pekerjaan sambilan seperti membuka kedai, berkebun atau menjadi tukang ojek. Gaji yang rendah diakui sebagai salah satu faktor yang menyebabkan maladministrasi birokrasi di Indonesia. Birokrasi di Indonesia mempunyai perilaku yang paling buruk di Asia. Burhanudin Muhtadi (2012) pula menyatakan bahwa maladministrasi birokrasi disebabkan oleh struktur organisasi yang terlalu luas dan besar. Sistem administrasi mengalami penyakit obesitas (gemuk) sehingga pekerjaan menjadi lambat. Ibarat seorang ibu tua yang berbadan gemuk disuruh berlari. Pegawai tidak memiliki kemampuan melakukan tugas pelayanan sebagaimana yang diharapkan oleh masyarakat.

\subsection{Maladministrasi Birokrasi Zaman Pasca Reformasi}

Reformasi birokrasi merupakan wacana sekaligus agenda utama dalam memperbaiki kualitas pelayanan publik setelah berakhirnya kekuasaan Suharto. Reformasi birokrasi merupakan sebuah perubahan besar dalam paradigma dan tata kelola pemerintahan di Indonesia. Ukuran keberhasilan reformasi birokrasi berdasarkan Peraturan Presiden nomor 81 tahun 2010 tentang grand design reformasi birokrasi 2010-2025 ditandai dengan tidak ada perilaku korupsi, tidak ada pelanggaran atas peraturan perundangan, semua program pembangunan selesai dengan baik, urusan perizinan selesai dengan cepat dan tepat, komunikasi dengan masyarakat baik, penggunaan waktu jam kerja efektif dan produktif, penerapan penghargaan (reward) dan hukuman (punishment) secara konsisten dan berkelanjutan. 
Hasil penelitian penulis di Kota Pekanbaru berdasarkan data kuantitaif yang berasal dari angket yang telah diisi oleh 250 pegawai yang bekerja di lima kantor yaitu kantor Dinas Kependudukan dan Pencatatan Sipil, Badan Pelayanan Terpadu dan Penanaman Modal, kantor Imigrasi Kelas I, kantor SAMSAT dan seluruh kantor camat di Kota Pekanbaru. Hasil penelitian menunjukkan bahwa tingkat perilaku maladministrasi birokrasi pegawai yang bekerja setelah masa reformasi lebih tinggi $(66,7 \%)$ berbanding pegawai yang bekerja sebelum masa reformasi (33.3\%).

\begin{tabular}{|c|c|c|c|c|c|c|}
\hline \multirow{3}{*}{$\begin{array}{c}\text { Perilaku } \\
\text { Maladministrasi } \\
\text { Birokrasi }\end{array}$} & \multicolumn{4}{|c|}{ Masa Bekerja } & \multirow{2}{*}{\multicolumn{2}{|c|}{ Jumlah }} \\
\hline & \multicolumn{2}{|c|}{$\begin{array}{c}\text { Bekerja } \\
\text { Setelah } \\
\text { Masa } \\
\text { Reformasi } \\
\end{array}$} & \multicolumn{2}{|c|}{$\begin{array}{c}\text { Bekerja } \\
\text { Sebelum } \\
\text { Masa } \\
\text { Reformasi }\end{array}$} & & \\
\hline & $\mathbf{N}$ & $\%$ & $\mathbf{N}$ & $\%$ & $\mathbf{N}$ & $\%$ \\
\hline $\begin{array}{l}\text { Tingkat Perilaku } \\
\text { Maladministrasi } \\
\text { Birokrasi }\end{array}$ & & & & & & \\
\hline $\begin{array}{l}\text { Tingkat Rendah } \\
\text { (Skor 16-24) }\end{array}$ & 128 & 65.3 & 68 & 34.7 & 196 & 100.0 \\
\hline $\begin{array}{l}\text { Tingkat Tinggi } \\
\text { (Skor 25-32) }\end{array}$ & 36 & 66.7 & 18 & 33.3 & 54 & 100.0 \\
\hline
\end{tabular}

Sumber: Hasil Olah Data Penelitian, 2018

Hal ini menunjukkan bahwa perilaku maladministrasi masih tetap kekal dan bahkan pegawai yang bekerja sesudah masa reformasi memiliki tahap perilaku maladministrasi birokrasi yang lebih tinggi berbanding pegawai yang bekerja setelah masa reformasi. Dengan menggunakan uji deskriptif pula menunjukkan bahwa terdapat jenis perilaku maladministrasi birokrasi (lihat Diagram 2) di lokasi penelitian yaitu kelalaian birokrasi dalam menyelesaikan urusan masyarakat (Mean=6,48), ketidakadilan birokrasi dalam memberikan layanan (Mean=5,07), penyalahgunaan wewenang $($ Mean=5,01) dan perilaku korupsi (Mean=5,15).

Rantai birokrasi yang panjang harus dipotong agar urusan masyarakat tidak memerlukan waktu yang lama dan biaya yang banyak. Kesejahteraan pegawai melalui bayaran gaji yang layak harus segera diwujudkan agar mereka tidak meminta uang bayaran tambahan kepada masyarakat. Penulis turut mengusulkan untuk membentuk modul khusus untuk perubahan mind set pegawai melalui program perbaikan akhlak. Pemerintah tidak cukup hanya melakukan reformasi hukum, reformasi sistem politik, reformasi ekonomi dan memandang rendah reformasi akhlak pegawai. Pemerintah juga harus melakukan reformasi mind set pegawai, bagaimana mengubah sifat jahat menjadi baik, amanah dan jujur, mengubah sifat pegawai yang berperilaku kasar dalam memberikan pelayanan berubah menjadi mesra, senyum dan penyayang, mengubah sifat pegawai yang suka mementingkan diri sendiri berubah menjadi lebih suka menduhulukan masyarakat dan mengubah sifat pegawai yang suka hidup bermewah-mewah berubah menjadi memilih hidup sederhana. 


\section{KESIMPULAN}

Perilaku maladministrasi birokrasi dalam perspektif sejarah di Indonesia sejak era kerajaan feodal hingga era reformasi menunjukkan bahwa birokrasi melayani kepentingan pihak penguasa. Istilah yang digunakan memang berubah mengikut zaman, tetapi perilaku mereka sama. Pada era pra kolonial birokrasi disebut priyayi \& abdi dalem, era kolonial Belanda disebut pangreh praja, sampai era orde lama, orde baru dan reformasi mereka hanya bertukar seragam dengan birokrasi modern namun tetap dengan spirit feodalisme (tabel 2 dibawah). Apa yang terjadi sekarang adalah masih sekedar perubahan peraturan perundang, terbukti maladministrasi birokrasi masih gagal diatasi. Mencegah perilaku maladministrasi birokrasi melalui penanaman dan pengamalan ajaran agama dan norma sosial adalah antara solusi yang dapat dilakukan oleh pihak pemerintah agar cita-cita reformasi birokrasi dapat terwujud.

\section{UCAPAN TERIMA KASIH}

Terima kasih penulis ucapkan kepada Rektor UIN Suska Riau yang telah memberikan izin untuk menyelesaikan studi S3 dan sebagian data Disertasi penulis gunakan sebagai bahan penulisan artikel ini.

\section{DAFTAR PUSTAKA}

[1].Agus Dwiyanto. (2008). Reformasi birokrasi publik di Indonesia. Yokyakarta: Gadjah Mada University Press.

[2].Ahmad Basuki. (2011). Pertanggungan Jawab Pidana Pejabat Atas Tindakan Mal-Administrasi Dalam Penerbitan Izin Di Bidang Lingkungan. Jurnal Perspektif 16 (4): 252-258.

[3].Anthony Reid. (2011). Asia Tenggara Dalam Kurun Niaga 1450-1680. Jakarta: Yayasan Obor Indonesia.

[4].Burhanudin Muhtadi. (2012). State Capture dan Korupsi Politik: Tantangan Reformasi Birokrasi. Jakarta: Penerbit Majalah Layanan Publik.

[5].Hans Dieter Ever dan Tilman Schiel. (1992). Kelompok-Kelompok Strategis: Studi Perbandingan tentang Negara, Birokrasi dan Pembentukan Kelas di Dunia Ketiga (terjemahan Indonesia). Jakarta: Yayasan Obor.

[6].Hartono. (2003). Panduan Investigasi Untuk Ombudsman Indonesia. Jakarta: The Asia Foundation.

[7].Ibnu Khaldun. (2008). Muqaddimah (Terjemahan Masturi Irham, Malik Supar dan Abidun Zuhri). Jakarta: Pustaka Al-Kautsar.

[8].Lijan. (2008). Reformasi Pelayanan Publik; Teori, Kebijakan dan Implementasi. Jakarta: Penerbit Bumi Aksara.

[9].Miftah Thoha. (2008). Ilmu Administrasi Publik Kontemporer. Jakarta: Penerbit Kencana Prenada Media Group. 
[10].Prajudi Admosudirdjo. (1990). Dasar-Dasar Administrasi Negara. Jakarta: Ghalia Indonesia.

[11].Samodra Wibawa. (2001). Negara-Negara Di Nusantara: Dari Negara Kota Hingga Negara Bangsa-Dari Modernisasi Hingga Reformasi Administrasi. Yogyakarta: Gadjah Mada University Press.

[12].Syed Abul Hasan Ali An Nadwy. (1951). Kerugian Dunia Karena Kemunduran Umat Islam. Surabaya: PT. Bina Ilmu

[13].Undang-Undang Nombor 37 Tahun 2008 Tentang Ombudsman Republik Indonesia.

[14].Wajong.(1962). Fungsi Administrasi Negara. Djakarta: Penerbit Djambatan.

[15].Zamakhsyari Dhofier. (1984). KH. Wahid Hasyim: Rantai Penghubung Peradaban Pesantren dengan Peradaban Indonesia Modern. Jurnal Prisma 8: 73-81. 